\title{
Antimicrobial susceptibility and characterization of extended-spectrum $\beta$-lactamases in Escherichia coli isolated from bovine mastitic milk in South Korea from 2012 to 2015
}

\author{
Dong-Seob Tark, ${ }^{*}$ Dong Chan Moon, $†$ Hee Young Kang, $†$ Su-Ran Kim, $†$ Hyang-Mi Nam, $†$ Hee-Soo Lee, $†$ \\ Suk-Chan Jung, $†$ and Suk-Kyung Lim† ${ }^{1}$ \\ ${ }^{*}$ Korea Zoonosis Research Institute, Chonbuk National University, 820-120 Hana-ro, Iksan, Jeonbuk 54531, Republic of Korea \\ †Bacterial Disease Division, Animal and Plant Quarantine Agency, 177 Hyeksin 8-ro, Gimcheon-si, Gyeongsangbuk-do 39660, Republic of Korea
}

\begin{abstract}
In this study, we aimed to assess trends in antimicrobial resistance and to investigate the characteristics of extended-spectrum $\beta$-lactamase (ESBL)-producing isolates from bovine mastitic milk from 2012 to 2015. A total of 374 Escherichia coli isolates were analyzed (154 in 2012, 113 in 2013, 76 in 2014, and 31 in 2015). No consistent trends in antimicrobial resistance of $E$. coli isolates occurred during the 4 -yr period. The most frequently observed resistance was tetracycline (23.3\%), followed by streptomycin (17.1\%), ampicillin (16.6\%), neomycin (11.8\%), and trimethoprim/sulfamethoxazole (11.2\%). Multidrug resistance was observed in $15.5 \%$ of isolates. Among these isolates, 15 (4.0\%) carried one or more $b l a_{\text {СтX-м }}$ and AmpC ESBL genes from 11 different farms, including $b l a_{\text {CTX-M-15 }}$ at 4 farms, $b l a_{\text {CTX-M-3 }}$ at 2 farms, bla $a_{\mathrm{CTX}-\mathrm{M}-1}$ at 3 farms, and $b l a_{\mathrm{CMY}-2}$ at 3 farms. This study is the first report of $b l a_{\mathrm{CTX} \text {-M-3 }}$-producing $E$. coli in dairy milk. Transfer of ESBL was observed in

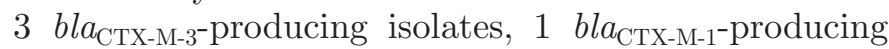
isolate, and all $3 b l a_{\mathrm{CMY}-2}$-producing isolates. Almost all $b l a_{\mathrm{CTX}-\mathrm{M}-15}$ and $b l a_{\mathrm{CTX}-\mathrm{M}-1}$ genes possessed an insertion sequence, ISECP1, upstream of the $b l a_{\mathrm{CTX} \text {-M }}$ gene. Identical pulsed-field gel electrophoresis profiles were also observed in $b l a_{\text {СТХ-м}}$-producing $E$. coli from the same farm. These results suggested that ESBL might spread by both clonal and horizontal spread in dairy farms in South Korea. Although no significant changes occurred in the antimicrobial resistance of $E$. coli during the 4-yr study period, the resistance rates and presence of ESBL were high compared with those in other countries. Thus, these findings suggest the importance of control measures for E. coli, particularly ESBL-producing bacteria, on dairy farms to reduce treatment failure and transmission to humans.
\end{abstract}

Received November 8, 2016.

Accepted January 22, 2017.

${ }^{1}$ Corresponding author: imsk0049@korea.kr
Key words: extended-spectrum $\beta$-lactamase, bovine mastitic milk, Escherichia coli, multidrug resistance

\section{INTRODUCTION}

Mastitis is the most common and economically significant disease affecting dairy cattle (Saini et al., 2012). A variety of bacteria are involved in mastitis, and gram-negative bacteria, such as Escherichia coli, are regarded as significant agents of environmentassociated bovine mastitis (Nam et al., 2009; Saini et al., 2012). Escherichia coli in mastitis is the cause of toxic mastitis, an acute or peracute form of disease that results in a higher incidence of death and culling of cattle (Burvenich et al., 2003).

Antimicrobial therapy is commonly used for prevention and control of mastitis. Unfortunately, treatment failure is common because of antimicrobial resistance (Suojala et al., 2013). A variety of antimicrobials have been approved for bovine mastitis treatment in Korea, including tetracyclines, sulfonamides, penicillins, aminoglycosides, fluoroquinolones, cephalosporins, and macrolides (KAHPA, 2016). Previous studies in Korea have shown that $E$. coli is the most common pathogen occurring among gram-negative bacteria (Nam et al., 2009). A better understanding of the resistance profile of $E$. coli isolates will improve our understanding of appropriate treatments for management of pathogenrelated disease.

The use of antimicrobials in agriculture has led to concerns regarding the potential for increased antimicrobial resistance on farms and the spread of antibioticresistant bacterial strains to human populations. In particular, third- and fourth-generation cephalosporins are critical for the treatment of serious infection with multidrug-resistant gram-negative bacteria (WHO, 2011). Extended-spectrum $\beta$-lactamase (ESBL)-producing Enterobacteriaceae are an important cause of both nosocomial and community infections (Kang et al., 2013). Moreover, a variety of CTX-M $\beta$-lactamases 
are present in food animals and animal products (Tamang et al., 2013). In Japan, the United Kingdom, and France, several CTX-M enzymes have been reported in bovine milk samples (Ohnishi et al., 2013; Dahmen et al., 2013; Timofte et al., 2014). However, few studies have reported the presence of these organisms in dairy milk in Korea, despite the major health risk of ESBLproducing $E$. coli in raw milk, particularly in countries where raw cheese is consumed. Therefore, in this study, we aimed to assess the antimicrobial resistance profiles and ESBL production of strains isolated from bovine milk.

\section{MATERIALS AND METHODS}

\section{Bacterial Isolates}

A total of $374 \mathrm{E}$. coli isolates from dairy mastitic milk were collected for this study, including 169 from the Animal and Plant Quarantine Agency (QIA; 76, 46, 16, and 31 isolates in 2012, 2013, 2014, and 2015, respectively) and 205 from 16 local veterinary service agencies (78,67, and 60 isolates in 2012, 2013, and 2014, respectively). A total of 4,437 quarter milk samples from lactating cows from 137 dairy herds nationwide were collected in the Mastitis Diagnostic Laboratory of the QIA from 2012 to 2015 . The proportion of samples having somatic cell counts of greater than 200,000 cells $/ \mathrm{mL}$ was $39.3 \%$ (1,742/4,437 samples). However, no information on the numbers of samples, cattle, and farms was available from 16 local veterinary service agencies. Sixteen local veterinary service laboratories submitted data to the QIA on the E. coli isolates each year. The laboratories are located in every province. Quarter samples were obtained from cattle affected by clinical and subclinical mastitis.

Bacterial examination of the samples with somatic cell counts of greater than 200,000 cells/mL at QIA and local veterinary clinics was carried out using standard laboratory techniques (National Mastitis Council, 1990). Escherichia coli was identified using a Vitek MS v2.0 system (bioMérieux, Durham, NC). One isolate per sample was selected for antimicrobial susceptibility tests.

\section{Antimicrobial Susceptibility Testing}

Minimum inhibitory concentrations (MIC) for E. coli were determined by the broth dilution method, using a commercially available Sensititer1 panel KRNV4F (Trek Diagnostic Systems, West Sussex, UK) according to the manufacturer's instructions. The antimicrobials tested included amoxicillin/clavulanic acid, ampicillin, cefoxitin, ceftiofur, cephalothin, chloramphenicol, ciprofloxacin, colistin, florfenicol, gentamicin, nalidixic acid, neomycin, streptomycin, tetracycline, and trimethoprim-sulfamethoxazole. Escherichia coli ATCC 25922 was used as quality control strain. The interpretation of MIC was carried out according to the Clinical and Laboratory Standards Institute (CLSI) guidelines (CLSI, 2015) or the guidelines of the Danish Integrated Antimicrobial Resistance Monitoring and Research Programme (2013) for streptomycin, neomycin, florfenicol, and colistin, for which CLSI breakpoints were not available. Antimicrobial resistance was defined as resistance to one or more antimicrobials, whereas multidrug resistance was defined as resistance to 3 or more antimicrobials.

\section{Detection of bla ${ }_{C T X-M}$ and ISECP1 Genes}

Phenotypic detection of ESBL production was performed using a double-disc synergy test according CLSI guidelines on ceftiofur-resistant isolates (CLSI, 2015). To confirm the presence of the $b l a_{\text {CTX-м }}$ genes, group-specific primers for the CTX-M-1 and CTX-M-9 families were used as described previously (Branger et al., 2005). Finally, the combination of the CTX-M-1G FL-F (Yu et al., 2007) or CTX-M-9G FL-R (Xiong et al., 2007) primer and the ISECP1U1 primer (Saladin et al., 2002) was used to amplify and sequence the complete $b l a_{\text {CTX-M }}$ gene. For CTX-M-positive isolates, PCR amplification and sequencing of the entire $b l a_{\text {TEM }}$ and $b l a_{\mathrm{SHV}}$ genes were performed as described previously (Rayamajhi et al., 2008). The genetic environment of the $b l a_{\text {СтХ-м }}$ gene identified in this study was investigated by PCR and by sequencing of the regions surrounding the gene. Forward primers of ISEcp1 and the CTX-M reverse consensus (MA2) primer were used to examine the presence of ISEcp1 genes (Saladin et al., 2002).

Screening for genes encoding 6 families of AmpCs was performed for cefoxitin-resistant isolates using multiplex PCR (Pérez-Pérez and Hanson, 2002). For amplification of the entire $b l a_{\mathrm{AmpC}}$ gene, PCR-positive isolates were re-amplified using specific primers as described previously (Pérez-Pérez and Hanson, 2002). All amplified samples were sequenced and compared with known sequences using the BLAST program at the National Center for Biotechnology Information website (http://www.ncbi.nlm.nih.gov/BLAST).

\section{Phylogenetic Grouping}

The method described by Clermont et al. (2000) was used to classify strains into ECOR phylogenetic groups; namely, A, B1, B2, and D. This method is based on a multiplex PCR for detection of 3 genetic markers, 
which were then used to assign the phylogenetic group based on a flowchart.

\section{Resistance Transfer and Replicon Typing}

Conjugation experiments were performed using sodium azide-resistant $E$. coli J53 as a recipient by filter mating, as described previously (Tamang et al., 2013). Transconjugants were selected on MacConkey agar plates supplemented with sodium azide $(150 \mathrm{mg} / \mathrm{L}$; Sigma, St. Louis, MO) and cefotaxime (2 $\mathrm{mg} / \mathrm{L})$ or cefoxitin $(32 \mathrm{mg} / \mathrm{L})$. The transconjugants were examined for the presence of $\beta$-lactamase genes and tested for susceptibility as described above for the wild strains.

Plasmid DNA was extracted from the transconjugants using the QuickGene plasmid isolation system (Fujifilm Corporation, Tokyo, Japan) following the manufacturer's protocol. Replicon typing of the isolated plasmid DNA was carried out using a PCR-based replicon-typing method, as described previously (Carattoli et al., 2005).

\section{Pulsed-Field Gel Electrophoresis}

Pulsed-field gel electrophoresis (PFGE) of genomic DNA of CTX-M $\beta$-lactamase-producing E. coli strains digested with XbaI (TaKaRa Bio Inc., Shiga, Japan) was carried out as described previously (Gautom, 1997) using a CHEF Mapper apparatus (Bio-Rad Laboratories, Hercules, CA). The PFGE conditions of $\mathrm{XbaI}$ macrorestriction analysis were $6 \mathrm{~V} / \mathrm{cm}$ for $19 \mathrm{~h}$ with pulse times ranging from 2.16 to $54.17 \mathrm{~s}$. The similarities of the restriction fragment length polymorphisms were analyzed using Bionumerics software, version 4.0 (Applied Maths, Sint-Martens-Latem, Belgium) to produce a dendrogram. Clustering was carried out by the unweighted-pair group method with arithmetic averages (UPGMA), based on the Dice similarity index.

\section{RESULTS}

\section{Antimicrobial Resistance}

A total of $374 \mathrm{E}$. coli isolates from bovine mastitic milk, collected from 2012 to 2015, were subjected to antimicrobial susceptibility testing (Table 1). For the 4 -yr period, no trends in antimicrobial resistance were observed. The most frequently observed resistance was tetracycline $(23.3 \%)$, followed by streptomycin (17.1\%), ampicillin (16.6\%), neomycin (11.8\%), and trimethoprim/sulfamethoxazole $(11.2 \%)$. Low resistance rates were observed for colistin $(0.5 \%)$, cefoxitin $(0.8 \%)$, and amoxicillin/clavulanic acid (1.6\%). Among the 374 isolates, 267 (71.4\%) were susceptible to the 15 antimicrobials tested in this study (Table 2). Furthermore, 107 isolates resistant to one more antimicrobials showed 40 different resistance patterns. Multidrug resistance was observed in $58(15.5 \%)$ isolates.

\section{Molecular Characterization of ESBL- Producing E. coli}

Out of $374 \mathrm{E}$. coli isolates examined, 15 and 3 were resistant to ceftiofur and cefoxitin, respectively. Of the 18 E. coli isolates resistant to ceftiofur or cefoxitin, a positive confirmatory test for the production of ESBLs was observed in 15 of the isolates. The ESBL-producing E. coli isolates carried 3 different $b l a_{\mathrm{CTX}-\mathrm{M}}$ genes and $1 b l a_{\text {CMY }}$ gene: $b l a_{\text {СТX-M-15 }}(\mathrm{n}=5)$, bla $a_{\text {CTX-M-3 }}(\mathrm{n}=4)$, $b l a_{\mathrm{CTX} \text {-M-1 }}(\mathrm{n}=3)$, and $b l a_{\mathrm{CMY}-2}(\mathrm{n}=3$; Table 3$)$. None of the isolates carried a $b l a_{\mathrm{SHV}}$ gene, whereas the $b l a_{\mathrm{TEM}-1}$ gene was detected in $4 b l a_{\text {CTX-M-3-producing isolates, } 3}$ $b l a_{\mathrm{CTX}-\mathrm{M}-1}$-producing isolates, and $1 b l a_{\mathrm{CTX-M-15}}$-producing isolate. All 12 E. coli isolates producing CTX-M ESBL were resistant to several non- $\beta$-lactam antimicrobial classes, including aminoglycosides, phenicols, (fluoro)quinolones, and antifolates. Most of ESBL-producing isolates were assigned to phylogenetic group A $(60 \%, 9 / 15)$, followed by D $(20 \%, 3 / 15)$ and B1 $(20 \%$, $2 / 15$ ); potential pathogenic group D was detected in 3 $b l a_{\mathrm{CTX}-\mathrm{M}-15}$-producing isolates. The $b l a_{\mathrm{ESBL}}$ genes were transferred by conjugation for 7 isolates, together with a single replicon for each isolate (F, FIB, and I1-Ir) and other resistance (gentamicin, neomycin, tetracycline, and trimethoprim/sulfamethoxazole). Polymerase chain reaction identified ISECP1 upstream of $b l a_{\text {CTX-M-15 }}$ in 4 out of $5 \mathrm{E}$. coli isolates and all bla $a_{\mathrm{CTX}-\mathrm{M}-1}$-producing isolates. The PFGE analysis of 15 ESBL-producing $E$. coli isolates showed a wide diversity of profiles, with 12 PFGE types (Table 2). However, a clonal relationship was observed in the isolates from the same farms (farms $\mathrm{B}$ and $\mathrm{C}$ ) and from different farms (farms $\mathrm{J}$ and $\mathrm{K}$ ).

\section{DISCUSSION}

In this study, we evaluated the resistance of isolates from bovine mastitis to common antibiotics in Korea. Notably, the overall resistance patterns in this study were similar to those of previous studies in Korea (Nam et al., 2009) and other countries (Saini et al., 2012; Thomas et al., 2015). Resistance to tetracycline was generally high, but those to fluoroquinolones and third-generation cephalosporins were low. However, the resistance rates in this study were higher than those from countries in the European Union (EU; Thomas et al., 2015) and Canada (Saini et al., 2012). For example, published resistance rates for tetracycline, amoxicillin/ clavulanic acid, and ceftiofur range from 9 to $14.3 \%$ to 


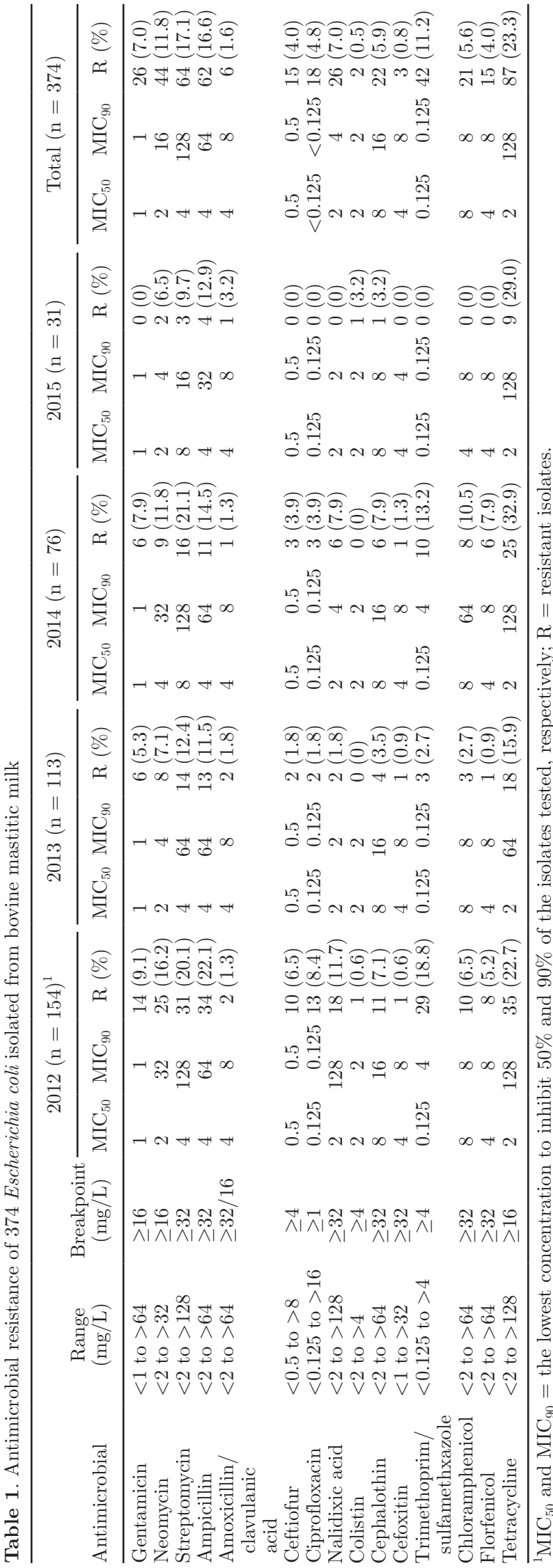

$23.3 \%$, from 0.2 to $1.1 \%$ to $1.6 \%$, and from 0 to $0.3 \%$ to $4.0 \%$ for the EU (Thomas et al., 2015), Canada (Saini et al., 2012), and our study, respectively. However, the antimicrobial resistant rates in this study were lower compared with those in a previous study performed by Nam et al. (2009); specifically, in the previous studies, resistance rates from 2003 to 2008 were $47.3 \%$ for tetracycline (versus $23.3 \%$ in our study) and $32.2 \%$ for ampicillin (versus $16.6 \%$ in our study). This decline may be related to the decreased use of antimicrobials in cattle. In Korea, about 97 to 121 and 56 to 65 t of antimicrobials were used each year in cattle during 2003 to 2008 and 2012 to 2014, respectively (QIA, 2010, 2014).

Resistance rates to third-generation cephalosporins were higher in this study $(4.0 \%)$ than in the EU $(0 \%$, 0/280 E. coli; Thomas et al., 2015), Canada (0.8\%, 3/394 E. coli; Saini et al., 2012), France (0.4\%, 6/1,427 E. coli and Klebsiella pneumoniae isolates; Dahmen et al., 2013), and Japan $(0.22 \%, 65 / 28,900$ gram-negative bacillus isolates; Ohnishi et al., 2013). This finding may result from the use of this class of antibiotic to treat cattle mastitis. Although the amount of total antibiotic consumption has been decreasing in cattle in Korea, the use of ceftiofur, a third-generation cephalosporin, has been increasing in veterinary medicine in Korea (QIA, 2014). Furthermore, almost all CTX-M-producing isolates have been shown to have additional resistance to antimicrobials that are frequently used for the treatment of mastitis in dairy farms. These results indicated that the choice of antimicrobials is very limited if these isolates infect the udders of cows. Thus, strict monitoring of dairy milk is needed to prevent the emergence and spread of ESBLs.

The ESBL-producing $E$. coli isolates in this study carried 3 different $b l a_{\mathrm{CTX}-\mathrm{M}}$ genes and $1 b l a_{\mathrm{CMY}}$ gene: $b l a_{\mathrm{CTX}-\mathrm{M}-15}, b l a_{\mathrm{CTX}-\mathrm{M}-3}, b l a_{\mathrm{CTX}-\mathrm{M}-1}$, and $b l a_{\mathrm{CMY}-2}$. The predominant types of ESBLs were also different between countries. In strains from mastitic milk, the $b l a_{\text {CTX-M-2 }}$ $(82 \%, 9 / 11), b l a_{\text {CTX-M-14 }}(67 \%, 4 / 6)$, and $b l a_{\text {CTX-M-15 }}$ $(40 \%, 2 / 5)$ genes were most prevalent in Japan (Ohnishi et al., 2013), France (Dahmen et al., 2013), and the United Kingdom (Timofte et al., 2014), respectively. A previous study by our group in 2008 showed that the bla $a_{\text {CTX-M-32 }}$ gene $(7 / 14,50.0 \%)$ was the most prevalent among ESBL-producing E. coli from dairy milk, followed by $b l a_{\text {CтX-M-14 }}(6 / 14,42.8 \%)$ and $b l a_{\text {CTX-M-15 }}(1 / 14$, $7.1 \%$ ) (Tamang et al., 2013). Interestingly, the prevalence of $b l a_{\text {СтX-M-15 }}$ has increased in cattle, becoming the most predominant genotype in our current study.

To the best of our knowledge, this study is the first report of $b l a_{\text {CTX-M-3 }}$ in dairy milk. After $b l a_{\text {CTX-M-3 } 3}$ was identified in cefotaxime-resistant Enterobacteriaceae isolates from a hospital in Warsaw, Poland (Gniadkowski et al., 1998), this gene has also been reported 
worldwide in both humans (Bonnet, 2004) and animals (Tamang et al., 2013). The $4 b l a_{\text {СтХ-м-3-producing iso- }}$ lates in this study showed multidrug resistance, including resistance to aminoglycosides, fluoroquinolones, tetracyclines, and folate pathway-targeting agents. In addition, conjugative plasmid $\mathrm{F}$ was detected in 3 CTX-M-3-producing isolates. This plasmid transferred with aminoglycoside resistance as well as resistance to third-generation cephalosporins by filter mating. The presence of a conjugative plasmid conferring multiple resistances in E. coli isolates could transfer the resistance to other susceptible bacteria, resulting in failure of mastitis treatment in cattle.

Reports on cefoxitin-resistant Enterobacteriaceae strains have shown the prevalence of CMY genes, DHA, and ACT-1-like plasmid-mediated AmpC $\beta$-lactamases in humans (Pérez-Pérez and Hanson, 2002) and animals (Rayamajhi et al., 2008). However, only one study, which was carried out in Switzerland in 2012, has reported CMY-2-producing E. coli in diary milk (Endimiani et al., 2012). In this study, all CMY-2-carrying E. coli isolates showed different PFGE patterns and were detected at different farms. These results indicated that these strains might have acquired their resistances individually. In contrast, all 3 strains in our study carried the identical conjugative Inc. I1-Ir plasmid. Hopkins et al. (2006) reported the identification of the Inc.I1 plasmid carrying the $b l a_{\mathrm{CMY}-2}$ and $b l a_{\mathrm{CMY}-7}$ genes from $E$. coli isolated from humans and cattle in the United Kingdom, Pakistan, and Gambia. In Korea, conjugative I1-Ir plasmids bearing $b l a_{\text {CTX-M14 }}$ and $b l a_{\text {СтX-M-32 }}$ were reported from $E$. coli isolated from various cattle samples, including feces, teats, and milk
(Tamang et al., 2013). As a successful epidemic replicon plasmid, the I1-Ir plasmid, which has a highly efficient conjugative system, can contribute to the emergence and spread of CMY in dairy cattle.

From the results of PFGE and phylogeny grouping, identical PFGE patterns were identified in 2 CTXM-15-producing isolates and 2 CTX-M-3-producing isolates in each farm. Although almost all isolates were nonpathogenic (groups A and B1), similar to a report from France (Dahmen et al., 2013), 1 clone producing $b l a_{\text {CTX-M-15 }}$ was detected in 2 isolates as potentially pathogenic (group D). Furthermore, this clone showed multiple resistances to aminoglycosides, fluoroquinolones, folate pathway inhibitors, and phenicols as well as $\beta$-lactams. Thus, further studies of pathogenic clones and multidrug resistance clones are needed for the prevention and treatment of mastitis.

In conclusion, analysis of $E$. coli from dairy milk from Korea showed higher antibiotic resistance than that in samples from other countries; in particular, $b l a_{\text {Стх-м }}{ }^{-}$ producing isolates were also resistant to antibiotics frequently used for mastitis treatment. The results from PFGE and plasmid analysis of ESBL- and AmpCproducing E. coli implied that a combination of clonal spread and horizontal transmission had facilitated the spread of $b l a_{\text {СтХ-м }}$ among $E$. coli from bovine milk in Korea. The presence of ESBL and AmpC plasmids in $E$. coli from dairy milk is concerning because these elements could result in treatment failure in dairy farms and transmission of bacteria to humans. Further work is needed to investigate the distribution of ESBL and AmpC plasmids in gram-negative bacteria and to reveal virulence that may be associated with mastitis,

Table 2. Antimicrobial resistance patterns of 374 Escherichia coli from dairy mastitic milk samples

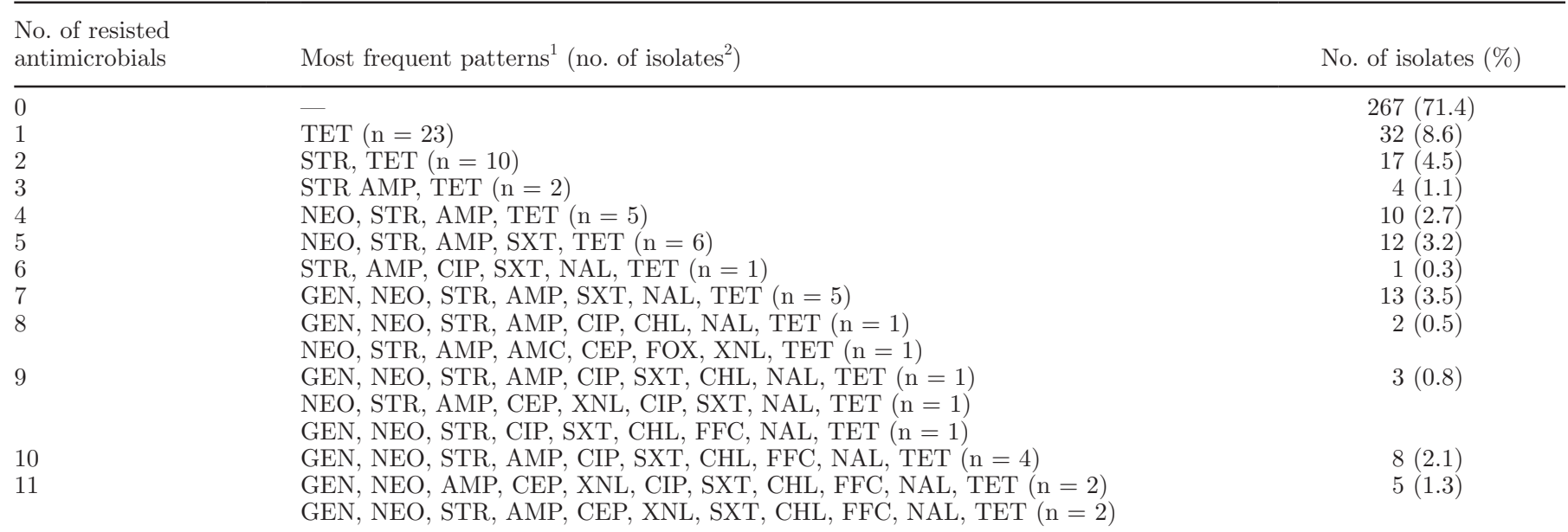

${ }^{1}$ TET = tetracycline; STR = streptomycin; AMP = ampicillin; NEO = neomycin; SXT = trimethoprim-sulfamethoxazole; SXT $=$ trimethoprim sulfamethoxazole; NAL = nalidixic acid; CEP = cephalothin; FOX = cefoxitin; XNL = ceftiofur; GEN = gentamicin; CIP = ciprofloxacin; CHL $=$ chloramphenicol; $\mathrm{FFC}=$ florfenicol

${ }^{2}$ Number of isolates observed with the most frequent pattern in each group. 
TARK ET AL.

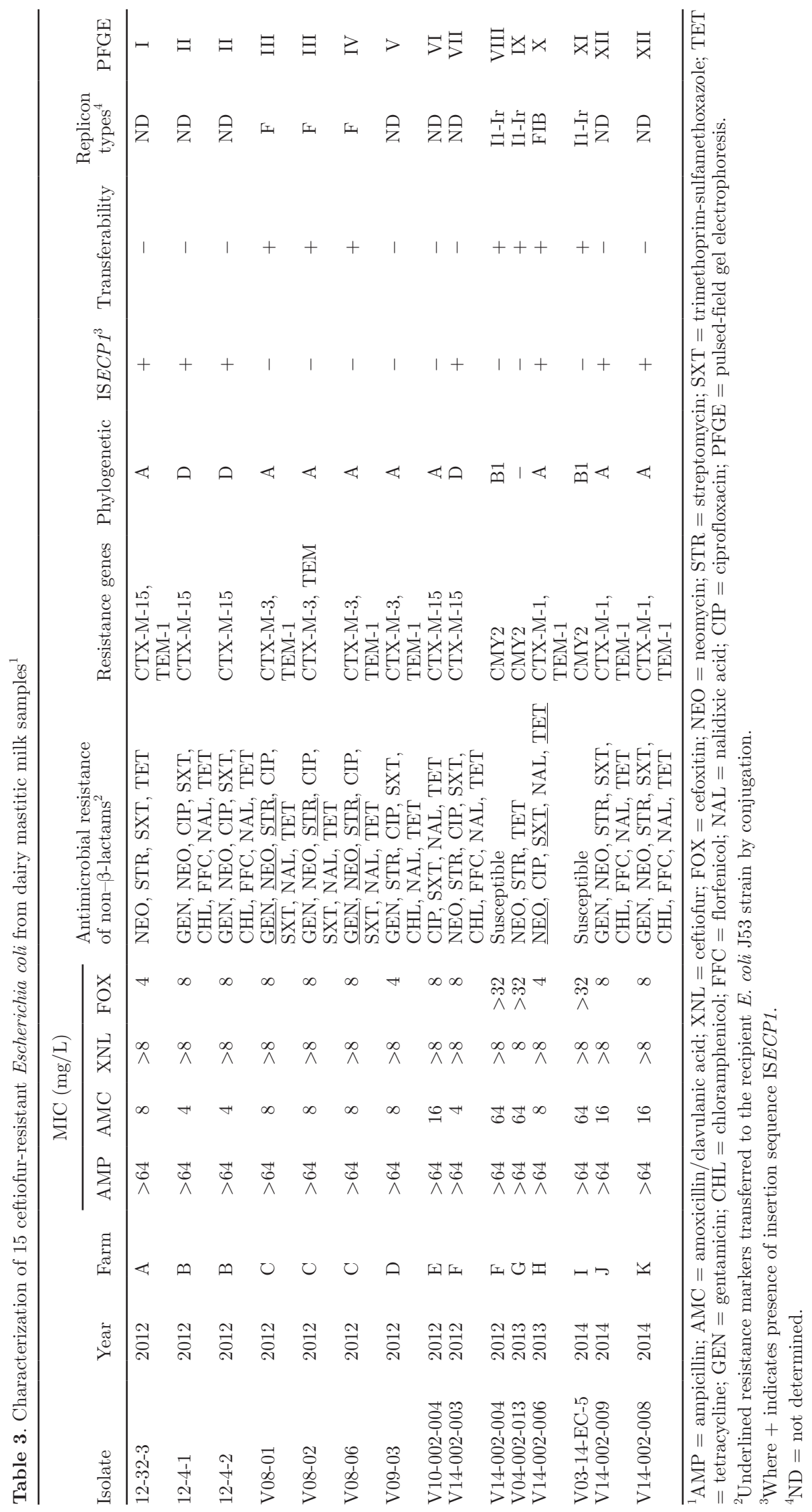


particularly in potentially pathogenic ESBL-producing isolates.

\section{ACKNOWLEDGMENTS}

This study was supported by a grant from the Animal and Plant Quarantine Agency, Ministry of Agriculture, Food, and Rural Affairs, Republic of Korea.

\section{REFERENCES}

Animal and Plant Quarantine Agency (QIA). 2010. Antimicrobial Use and Monitoring in Animals and Animal Products. QIA, Gimcheon, South Korea.

Animal and Plant Quarantine Agency (QIA). 2014. Antimicrobial Use and Monitoring in Animals and Animal Products. QIA, Gimcheon, South Korea.

Bonnet, R. 2004. Growing group of extended-spectrum $\beta$-lactamases: The CTX-M enzymes. Antimicrob. Agents Chemother. 48:1-14.

Branger, C., O. Zamfir, S. Geoffroy, G. Laurans, G. Arlet, H. V. Thien, S. Gouriou, B. Picard, and E. Denamur. 2005. Genetic background of Escherichia coli and extended-spectrum $\beta$-lactamase type. Emerg. Infect. Dis. 11:54-61.

Burvenich, C., V. Van Merris, J. Mehrzad, A. Diez-Fraile, and L. Duchateau. 2003. Severity of E. coli mastitis is mainly determined by cow factors. Vet. Res. 34:521-564.

Carattoli, A., A. Bertini, L. Villa, V. Falbo, K. L. Hopkins, and E. J. Threlfall. 2005. Identification of plasmids by PCR-based replicon typing. J. Microbiol. Methods 63:219-228.

Clermont, O., S. Bonacorsi, and E. Bingen. 2000. Rapid and simple determination of the Escherichia coli phylogenetic group. Appl. Environ. Microbiol. 66:4555-4558.

Clinical and Laboratory Standards Institute. 2015. Performance Standards for Antimicrobial Susceptibility Testing; Twenty-Fifth Informational Supplement. M100-S25. CLSI, Wayne, PA.

Dahmen, S., V. Métayer, E. Gay, J. Y. Madec, and M. Haenni. 2013. Characterization of extended-spectrum beta-lactamase (ESBL)carrying plasmids and clones of Enterobacteriaceae causing cattle mastitis in France. Vet. Microbiol. 162:793-799.

Danish Integrated Antimicrobial Resistance Monitoring and Research Programme. 2013. Use of antimicrobial agents and occurrence of antimicrobial resistance in bacteria from food animals, foods and humans in Denmark. ISSN 1600-2032. http://www.danmap.org/.

Endimiani, A., I. Bertschy, and V. Perreten. 2012. Escherichia coli producing CMY-2 $\beta$-lactamase in bovine mastitis milk. J. Food Prot. 75:137-138.

Gautom, R. K. 1997. Rapid pulsed-field gel electrophoresis protocol for typing of Escherichia coli O157:H7 and other gram-negative organisms in 1 day. J. Clin. Microbiol. 35:2977-2980.

Gniadkowski, M., I. Schneider, A. Palucha, R. Jungwirth, B. Mikiewicz, and A. Bauernfeind. 1998. Cefotaxime-resistant Enterobacteriaceae isolates from a hospital in Warsaw, Poland: Identification of a new CTX-M-3 cefotaxime-hydrolyzing beta-lactamase that is closely related to the CTX-M-1/MEN-1 enzyme. Antimicrob. Agents Chemother. 42:827-832.

Hopkins, K. L., E. Liebana, L. Villa, M. Batchelor, E. J. Threlfall, and A. Carattoli. 2006. Replicon typing of plasmids carrying CTX-M or CMY beta-lactamases circulating among Salmonella and Escherichia coli isolates. Antimicrob. Agents Chemother. 50:3203-3206.

Kang, C. I., M. K. Cha, S. H. Kim, K. S. Ko, Y. M. Wi, D. R. Chung, K. R. Peck, N. Y. Lee, and J. H. Song. 2013. Clinical and molecular epidemiology of community-onset bacteremia caused by extended-spectrum $\beta$-lactamase-producing Escherichia coli over a 6-year period. J. Korean Med. Sci. 28:998-1004.

Korea Animal Health Products Association (KAHPA). 2016. Search for animal health products. Accessed Oct. 4, 2016. http://www. kahpa.or.kr/Document/Menu/FRAME.asp.

Nam, H. M., S. K. Lim, H. M. Kang, J. M. Kim, J. S. Moon, K. C. Jang, J. M. Kim, Y. S. Joo, and S. C. Jung. 2009. Prevalence and antimicrobial susceptibility of gram-negative bacteria isolated from bovine mastitis between 2003 and 2008 in Korea. J. Dairy Sci. 92:2020-2026.

National Mastitis Council. 1990. Microbiological Procedures for the Diagnosis of Bovine Udder Infection. 3rd ed. National Mastitis Council, Inc., Arlington, VA.

Ohnishi, M., A. T. Okatani, K. Harada, T. Sawada, K. Marumo, M. Murakami, R. Sato, H. Esaki, K. Shimura, H. Kato, N. Uchida, and T. Takahashi. 2013. Genetic characteristics of CTX-M-type extended-spectrum- $\beta$-lactamase (ESBL)-producing Enterobacteriaceae involved in mastitis cases on Japanese dairy farms, 2007 to 2011. J. Clin. Microbiol. 51:3117-3122.

Pérez-Pérez, F. J., and N. D. Hanson. 2002. Detection of plasmidmediated AmpC beta-lactamase genes in clinical isolates by using multiplex PCR. J. Clin. Microbiol. 40:2153-2162.

Rayamajhi, N., S. G. Kang, D. Y. Lee, M. L. Kang, S. I. Lee, K. Y. Park, H. S. Lee, and H. S. Yoo. 2008. Characterization of TEM-, SHV- and AmpC-type beta-lactamases from cephalosporin-resistant Enterobacteriaceae isolated from swine. Int. J. Food Microbiol. 124:183-187.

Saini, V., J. T. McClure, D. Léger, G. P. Keefe, D. T. Scholl, W. Morck, and H. W. Barkema. 2012. Antimicrobial resistance profiles of common mastitis pathogens on Canadian dairy farms. J. Dairy Sci. 95:4319-4332.

Saladin, M., V. T. Cao, T. Lambert, J. L. Donay, J. L. Herrmann, Z Ould-Hocine, C. Verdet, F. Delisle, A. Philippon, and G. Arlet. 2002. Diversity of CTX-M beta-lactamases and their promoter regions from Enterobacteriaceae isolated in three Parisian hospitals. FEMS Microbiol. Lett. 209:161-168.

Suojala,, L., L. Kaartinen, and S. Pyörälä. 2013. Treatment for bovine Escherichia coli mastitis - An evidence-based approach. J. Vet. Pharmacol. Ther. 36:521-531.

Tamang, M. D., H. M. Nam, M. Gurung, G. C. Jang, S. R. Kim, S. C. Jung, Y. H. Park, and S. K. Lim. 2013. Molecular characterization of CTX-M $\beta$-lactamase and associated addiction systems in Escherichia coli circulating among cattle, farm workers, and the farm environment. Appl. Environ. Microbiol. 79:3898-3905.

Thomas, V., A. de Jong, H. Moyaert, S. Simjee, F. El Garch, I. Morrissey, H. Marion, and M. Vallé. 2015. Antimicrobial susceptibility monitoring of mastitis pathogens isolated from acute cases of clinical mastitis in dairy cows across Europe: VetPath results. Int. J. Antimicrob. Agents 46:13-20.

Timofte, D., I. E. Maciuca, N. J. Evans, H. Williams, A. Wattret, J. C. Fick, and N. J. Williams. 2014. Detection and molecular characterization of Escherichia coli CTX-M-15 and Klebsiella pneumoniae SHV-12 $\beta$-lactamases from bovine mastitis isolates in the United Kingdom. Antimicrob. Agents Chemother. 58:789-794.

World Health Organization. 2011. Critically Important Antimicrobials for Human Medicine. 3rd Revision. Accessed Feb. 2, 2015. http:// apps.who.int/iris/bitstream/10665/77376/1/9789241504485_eng. pdf.

Xiong, Z., T. Li, Y. Xu, and J. Li. 2007. Detection of CTX-M-14 extended-spectrum beta-lactamase in Shigella sonnei isolates from China. J. Infect. 55:e125-e128.

Yu, Y., S. Ji, Y. Chen, W. Zhou, Z. Wei, L. Li, and Y. Ma. 2007. Resistance of strains producing extended-spectrum $\beta$-lactamases and genotype distribution in China. J. Infect. 54:53-57. 